\title{
Management Strategies for Reservoirs Fisheries
}

\section{Thankam Theresa Paul', Rani Palaniswamy1, S Manoharan', Usha Unnithan ${ }^{1}$ and Sarkar UK ${ }^{2}$}

${ }^{1}$ ICAR - Central Inland Fisheries Research Institute, Kochi centre, CMFRI Campus, Kochi, India

${ }^{2}$ ICAR - Central Inland Fisheries Research Institute, Barrackpore, Kolkata, India

\begin{abstract}
Reservoirs nicknamed as sleeping giants have been identified as the nearest possible alternative source of fish production only recently. But the average fish productivity of reservoirs in India is nearly $30 \mathrm{Kg} / \mathrm{ha}$ and this is not sufficient enough to match the ever-doubling rate of population demands. The paper thus discusses the various enhancement strategies adopted for Indian reservoirs. The paper emphasizes enhancing fish production by manipulating biological and physical basis of production along with other strategies for maximizing fishing in the reservoirs. The challenges involved in fish production using various strategies have also been discussed.
\end{abstract}

Keywords: Reservoirs; Management strategy; Production

\section{Introduction}

The ever-widening gap between the increased demand for fish and the apparent limited growth for natural production from marine capture fisheries has invoked the need for various forms of culture based systems globally. This includes the enhancement of natural production in larger water bodies such as natural lakes and man-made reservoirs.

The reservoir which is a large man-made ecosystem without a parallel in nature wherein the co-existence of fluviatile as well as lacustrine ecosystem occur, has been conceived as a pillar for development in India in the context of agricultural self-sustenance by our erstwhile Prime Minister, Pandit Jawaharlal Nehru. These reservoirs which were constructed for the purpose of generation of hydro-electric power, water supply, irrigation etc. were not utilized as fishery enhancement units in the earlier days. This paper deals with various fishery enhancement tools that can be or were used in Indian reservoirs.

Any fishery enhancement activity in a reservoir should be based on the morpho-edaphic factors of the reservoir [1]. Keeping this requirement in view, the broad classification of reservoirs into three on the basis of the catchment area as large, medium and small may be adopted here to advise on the morphometric factors affecting fishery enhancement in reservoirs. A broad knowledge of the factors influencing the fishery enhancement should be taken up.

\section{Current Status of Reservoirs in India}

There are many reservoirs in India extending over an area of 3.0 million ha and distributed under divergent geo-climatic, morphometric and edaphic environments. Table 1 represented an estimate of the reservoir resources of India.

The average productivity from these reservoirs in India is nearly 30 $\mathrm{Kg} / \mathrm{ha}$ against the production potential of $250 \mathrm{Kg} / \mathrm{ha}$. These resources are evidently under utililsed. Recently, NFDB has adopted a few reservoirs and they have documented a higher production as detailed in Table 2.

\section{Current Fisheries Status of India}

When the lengthy coastline of $8129 \mathrm{~km}$ and continental shelf of 2.02 mill. $\mathrm{km}^{2}$ had been a major source of Indian marine capture fisheries, the rivers and the reservoirs constructed across them along with the vast lacustrine and floodplain system became the major source of inland capture fisheries. The contribution of marine capture fisheries to the Indian fisheries is lesser (34\%) as compared to Inland capture fisheries $(38.79 \%)$. The lack of proper accounting of the contribution of inland

\begin{tabular}{|c|c|c|c|}
\hline Type of reservoir & Small & Medium & Large \\
\hline Number & 19,134 & 180 & 56 \\
\hline Area (ha) & $14,85,557$ & $5,27,541$ & $11,40,268$ \\
\hline
\end{tabular}

Table 1: Reservoir resources of India.

\begin{tabular}{|c|c|c|c|}
\hline Type of reservoir & Small & Medium & Large \\
\hline Average fish yield (Kg/ha) & 174 & 94 & 33 \\
\hline
\end{tabular}

Table 2: Fish yield (Kg/ha) from Indian reservoirs under NFDB scheme.

fisheries to the total fish production of India has affected the proper representation of inland capture fisheries, on a national level.

Though the production from inland fisheries is double the marine fisheries, the quantity contributed in terms of capture or capture-cumculture fisheries may be enhanced from these inland water bodies in order to meet the ever-climbing demand for fish. The recent strategies adopted in fisheries production are named as enhancement strategies. The enhancements are interventions in the physical or ecological functioning of aquatic resources which are dependent on a series of biotic and abiotic factors [2]. The purpose of fishery enhancement strategies varies from fisheries development aspects which certainly deal with optimising the utilisation of whole ecosystem and selective fishing down of the food webs, to manipulations of stock, species and environment which ensure stock increment and offering of favourable habitats through habitat modifications to closed enhancements including cages, pens and raceways.

\section{Factors Affecting Fishery in a Reservoir}

Biotic and abiotic may be the two broad types of factors that determine the productivity from any reservoir. The abiotic factors which are related to the geographical location and microclimate of the reservoir are independent variables beyond the control of fishery managers. Some of such factors include physical factors (morphometric,

${ }^{*}$ Corresponding author: Thankam Theresa Paul, ICAR - Central Inland Fisheries Research Institute, Kochi centre, CMFRI Campus, Kochi, India, Tel: 0484239 4867; E-mail: thankamtheresa@gmail.com

Received June 15, 2017; Accepted July 19, 2017; Published July 21, 2017

Citation: Paul TT, Palaniswamy R, Manoharan S, Unnithan U, Sarkar UK (2017) Management Strategies for Reservoirs Fisheries. J Aquac Res Development 8: 492. doi: 10.4172/2155-9546.1000492

Copyright: @ 2017 Paul TT, et al. This is an open-access article distributed under the terms of the Creative Commons Attribution License, which permits unrestricted use, distribution, and reproduction in any medium, provided the original author and source are credited. 
climatic, edaphic) and hydrologic factors. The biological factors such as food-web, community and evolutionary specifics also determine the fishery productivity from any natural environment.

The production potential of culture-based fisheries is strongly linked to ecosystem productivity, which is mainly based on physical and biological factors and also on the basis of natural production. Manipulations in these factors may change the natural carrying capacity which would eventually influence production from any system. The enhanced production of fisheries may be obtained using these factors in the following ways:

\section{Enhancement using natural production basis}

The enhancement methods using natural production basis in reservoirs vary with the size of the reservoirs. Mesh size and gear restrictions are among the most easily applied management regulations. Mesh size restriction involves regulation of the exploitation rate or the exploitation pattern through effort control and is practiced in Indian reservoirs during stocking programme. These regulations result in utilising maximum productivity of ecosystems by exploiting the small pelagics, or by fishing down the ecosystem or by reducing the predator masses [3]. A typical example of fishery enhancement on the natural production basis is adopted in Peechi reservoir after banning stocking in the system by Forest department (Figure 1).

As a result of which the fisher's community has adopted fishery enhancement strategy of maximising the output from the system by manipulating the mesh sizes of the gear used. This strategy is best suited for reservoirs managed under conservation strategy.

\section{Enhancements through manipulation of the physical base of production}

This strategy involves the manipulation of physical factors affecting fish production. Latitude determines the physical factors like climatic conditions, which again control variables such as temperature, light, annual insolation, seasonal variation, wind and precipitation. All these play a major role in the nutrient cycles and hence the regeneration of biomass. These enhancements may be classified into edaphic, nutrient, hydrological and habitat enhancements.

Edaphic enhancements: The edaphic conditions determine the chemical composition of the soil in the surrounding watershed, and thus the supply of nutrients and trace elements for organic synthesis [4]. Thus, the enhancements based on manipulations in edaphic factors depend on the nutrient status of the water body and soil along with the physical variables such as specific conductivity, total alkalinity etc. [5]. The morphology of a reservoir, particularly area, volume, depth, and shoreline development or gradient, is also of major importance to the productivity [4]. The mean depth is a single morphometric parameter used to estimate the production potential of a reservoir [6].

\section{Average productivity $(\mathrm{Kg} / \mathrm{ha})$}

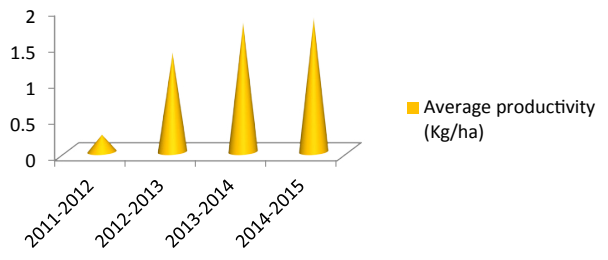

Figure 1: Average productivity of Peechi reservoir, Kerala.

\begin{tabular}{|c|c|c|}
\hline Physico-chemical variables & Peechi Reservoir & Pothundi Reservoir \\
\hline pH & $6.37-7.07$ & $6.2-7.04$ \\
\hline Conductivity $(\mathrm{mS})$ & $51.27-83.22$ & $51.8-84.8$ \\
\hline Turbidity (NTU) & $0.45-1.25$ & $0.45-0.95$ \\
\hline Alkalinity (ppm) & $28.8-52.13$ & $36-48.8$ \\
\hline D. O. $(\mathrm{ppm})$ & $5.92-6.93$ & $5.71-6.79$ \\
\hline Hardness (ppm) & $14.67-15.33$ & $14.93-20.0$ \\
\hline Phosphate $(\mathrm{ppm})$ & $0.054-0.15$ & $0.012-0.022$ \\
\hline Nitrate $(\mathrm{ppm})$ & $0.8-1$ & $1.0-7.0$ \\
\hline Silicate $(\mathrm{ppm})$ & $0.031-0.065$ & $0.032-0.065$ \\
\hline Chlorophyll $(\mathrm{mg} / \mathrm{sq} . \mathrm{m})$ & $4.257-5.118$ & $6.2-7.34$ \\
\hline Fish yield $(\mathrm{Kg} / \mathrm{ha})$ & 0.898 & 15.7 \\
\hline
\end{tabular}

Table 3: Exhibits the fishery productivity and nutrient status of two reservoirs in Kerala.

\begin{tabular}{|c|c|c|c|}
\hline Dam Name & Sathanur & Krishnagiri & Vidur \\
\hline Fish yield (t/year) & 128.7 & 33.8 & 4.12 \\
\hline $\mathrm{pH}$ & 8.8 & 8.6 & 8.2 \\
\hline DO & 8.5 & 8.2 & 7.1 \\
\hline EC (mS) & 320 & 425 & 38.1 \\
\hline Nitrate (ppm) & 3.2 & 4.4 & 15.9 \\
\hline silicate (ppm) & 1.2 & 1.18 & 0.466 \\
\hline Total Hardness (ppm) & 254 & 76 & 134 \\
\hline Alkalinity (ppm) & 145 & 145 & 134 \\
\hline
\end{tabular}

Table 4: Physico-chemical variables and fish yield of Tamilnadu reservoir.

Nutrient enhancement: Lakes and reservoirs do not maintain their fertility unless an external loading of nutrients is continually applied through their inflowing rivers and from rainwater. Typically, the nutrients tend to accumulate in the water basins due to evaporation, biological activities, and sediment interaction. In India, the nutrient status of most of the reservoirs is low and this does not indicate low productivity from the system. Phosphate very seldom exceeds $0.1 \mathrm{mg}$ $1^{-1}$ in reservoirs free from pollution. Quick recycling of nutrients and rapid turnover rates of phosphate in the system makes it difficult to ascertain the reservoir productivity based on the status of phosphate. Nitrate nitrogen in water in Indian reservoirs exceeds $0.5 \mathrm{mg}^{-1}$. Total alkalinity and the specific conductivity also indicate the production potential of a reservoir. Most of the reservoirs in Kerala portray a low status in terms of nutrients, specific conductivity $(<100 \mathrm{mS})$ and total alkalinity $(<100 \mathrm{ppm})$ with a low primary productivity and plankton diversity.

The low nutrient status of the reservoirs of Kerala depicted by the presence of silicates and phosphates in traces and the low nitrate levels may be correlated with low fish yields (Table 3). But the reservoirs drained by the rivers from Western Ghats in Tamil Nadu such as Sathanur, Krishnagiri and Vidur exhibited a better picture of fishery status in reservoirs (Table 4). Despite high alkalinity and physical conductivity, Krishnagiri is showing low fish yield compared to Sathanur and Vidur reservoirs $[7,8]$. So, it may be concluded that nutrient status alone cannot decide the fishery yield from a reservoir [9].

But still, the enhancement of nutrient status in reservoirs otherwise called fertilization directly has a positive impact on fish production. Nutrient enhancement has been done in Nongmahir (70 ha) and Kyrdemkulai ( $80 \mathrm{ha}$ ) reservoirs of North East India by applying poultry manure, urea and single super phosphate.

Temperature dependent enhancement: Discharge from the lower layer of water in the reservoir which would be lowered temperatures in the receiving tail water may be used for stocking with exotic cold-water species (assuming that the water is sufficiently oxygenated). 
Hydrologic enhancements: It is another type of enhancement based on physical factors of production by inducing flood pulse and manipulating drawdown and inflow of reservoirs in accordance with the life cycles of important species [10]. This is not practiced in the Indian subcontinent.

Habitat enhancements: Habitat enhancements are meant to improve on the specific requirements of fish species and communities for feeding, breeding, nursery and shelter. This enhancement strategy based on physical factors varies with the type of fisheries in the reservoir [11]. The strategy for culture-based fisheries involves preparation of reservoirs in planning stage which encompasses removal of trees and general preparation of the reservoir bed for effective harvesting and destroying potential spawning or nursery habitats of unwanted species. This strategy was practiced in Chillar and Benisagar reservoirs of Madhya Pradesh and Hirakud dam of Orissa.

The strategies adopted for capture based fisheries include habitat restoration via offering of specialised structures to enhance longrange migrations and short-range movements. Construction of fishways to maintain or restore longitudinal migrations (upstream and downstream) is practiced in India in Farracka barrage reservoir (Pantulu). Adaptive fish pass technology suiting the local reservoir should be constructed to allow upstream as well as downstream passes of fish [12]. Enhancements of fisheries through offering specialised habitats of FEDs through the involvement of local fishermen had been practiced in many reservoirs in Kerala (Thoopu).

\section{Enhancements based on biological basis of production}

Biological enhancements can be done through manipulation of the fish community and culture based systems: from open to closed aquaculture. Fish community can be manipulated using species introductions and stock enhancements.

Species introduction: Species introductions into a reservoir system area controversial issue on account of the competition offered by the introduced species at various levels to the endemic fishes of the system [13]. Oreochromis mossambicus, Ctenopharyngodon idella, Hypophthalmichthys molitrix, Clarias gariepinus and Cyprinus carpio have gained entry to Indian reservoir system. The impacts of these entries were already discussed. Accidental introduction of Silver carp is a great example in the Indian context.

Stock enhancements: This enhancement strategy has been concluded into 4 types mainly single species, multiple species, predator enhancement and predator control. Stock enhancement may be done either by altering the species itself or by altering the relative stock density [14]. Usually, in India, these include mixtures of bottom feeders, higher vegetation feeders and pelagic zooplankton and phytoplankton feeders, which is otherwise a relative proportion of Indian Major Carps. This multispecies enhancement strategy is usually applied across India.

Non-predator introductions in reservoirs could be related to the plasticity in feeding niches and other life-history requirements of many of the detritivorous or herbivorous species used. This then would allow a greater degree of "niche-packing" and restricts effects on long-term stability of the existing indigenous communities. The introduction of grass carp in Gobindsagar reservoir was a similar enhancement strategy. The resilience of species to introductions and "niche-plasticity" may also be a function of the adaptation of the species communities present in the highly predictable conditions of reservoirs $[15,16]$.

Though predator enhancement is also a strategy offishery production in a situation to control weed fishes, predator control strategy is found to be the best option. Though the former is not practiced in India, the latter was tried in Tungabhadra reservoir. The opposite management option is to decrease predators in order to release fish production from desirable fish species at lower trophic levels. Eradication of predators by netting adults also appears to be done mainly in smaller reservoirs. In Tungabhadra, removal of predators has been done using Alvi. Longterm removal of predators, particularly in larger reservoirs, is virtually impossible to achieve.

\section{Enhancements through Culture-Based Systems: From Open to Closed Aquaculture}

Though interventions from coves to finger ponds have been applied in reservoirs, the best method used would be cage culture. Another step towards more closed systems comparable with more intensive forms of land-based aquaculture is cage-cultures. Cultures have the advantage above land-based systems that they do not make claims on scarce land resources. Cage cultures have developed independently, but are often closely associated with other forms of enhancement [17]. Among the synergetic effects are stocking through escapement of cultured species from cages to the wild and through the eutrophication of the lake environment through the leaching of nutrients and excess food into the natural environment $[18,19]$

\section{Challenges in Enhancement Strategies}

\section{Available natural production basis}

Fishing the reservoir without selective methods may maximise output. Moreover, in fluctuating systems, the spatial and temporal dynamics of small-scale fishing effort may be highly adapted to the changing availability of fish and hence small-scale fisheries may utilise their production in a more efficient and biologically sounder way than more technologically advanced fisheries [20]. The lack of quantitative information on basic fisheries information for small-scale inland fisheries on a broad scale needs to be remedied [21]. There is a need to investigate spatial and temporal dynamics of fishing effort in smallscale fisheries and their capacity to react and adapt to fluctuating environments [22].

\section{Physical basis of production}

Any outside water management that alters the flow regime or the system connectivity will have consequences for the productivity. For lakes and reservoirs, more research is needed to fully understand impact of hydrological and edaphic fluctuations in relation to productivity [23].

\section{Biological basis for production}

The pelagic zone in many reservoirs has no indigenous lacustrine fish fauna and therefore remains uninhabited and under-utilised from a fishery perspective. In such cases, the introduction of low trophic level fish species in the food web for harvesting should be considered [24]. Documentation of the impact of introducing lacustrine species to man-made reservoirs should be weighed against the potential increase in productivity. Stockings of indigenous or non-indigenous fish species is an enhancement strategy in both lakes and reservoirs. In addition, meta-analysis of existing experimental data and information on enhancement practices is needed.

\section{Conclusion}

Reservoirs with such a vast area of 3 million ha are observed to be inefficiently used in India. The possible interventions such as effective utilisation of pelagic fishes in reservoirs, data management of 
Citation: Paul TT, Palaniswamy R, Manoharan S, Unnithan U, Sarkar UK (2017) Management Strategies for Reservoirs Fisheries. J Aquac Res Development 8: 492. doi: 10.4172/2155-9546.1000492

indigenous fishes, impact studies related to hydrological and edaphic fluctuations on fish productivity may be taken up for the immediate future. Though all these management measures lead to enhancement, a combination of enhancement strategies would be wise in the Indian context.

\section{Acknowledgments}

I am thankful to Director, CIFRI for funding the project under ICAR funding scheme. I express all my gratitude towards him for his support.

\section{References}

1. Cestti R, Malik RPS (2012) Impacts of large dams: A global assessment: Water resources development and management. Springer-Verlag, Berlin Heidelberg.

2. Jitesh VK, Ananthan PS, Asha L (2014) Fish and fisheries management status of Itiadoh reservoir, Maharashtra State. Eco Env \& Cons 20: 1653-1659.

3. Jindal R, Singh H, Sharma C (2014) Fish diversity of Pong dam reservoir and Harike wetland 3: 232-240.

4. Ryder RA (1978) Fish yield assessment of large lakes and reservoirs - A prelude to management. Ecology of freshwater fish production. Blackwell Scientific Publications, Oxford, UK.

5. Craig JF (2000) Sustainable fish production in Lake Nasser: Ecological basis and management policy. World Fish Center, Penang, Malaysia.

6. Agaypi MZ (2000) A note on the relationship between catch and water level. Sustainable fish production in Lake Nasser: Ecological Basis and Management Policy, Malaysia.

7. Sugunan VV (1995) Reservoir fisheries of India. FAO Fisheries Technical Paper. No. 345. Rome, FAO.

8. Sarkar UK, Pathak AK, Tyagi LK, Srivastava SM, Singh SP (2013) Biodiversity of freshwater fish of a protected river in India: comparison with unprotected habitat. Rev Biol Trop 61: 161-172.

9. Amarasinghe US, De Silva SS, Nissanka C (2002) Evaluation of the robustness of predictive yield models based on catchment characteristics using GIS for reservoir fisheries in Sri Lanka. Fisheries Management and Ecology 9: 293-302

10. Bell J, Jamu D (2003) Assessing the potential for restocking, habitat enhancement, fish sanctuaries and aquaculture to restore production of Chambo in Malawi. World Fish Center, Compass, Fisheries Department, Lilongwe, Malawi.
11. Agostinho CS, Pelicice FM, Marques EE, Soares AB, Almeida DA (2011) All that goes up must come down? Absence of downstream passage through a fish ladder in a large Amazonian river. Hydrobiologia 675: 1-12.

12. Agostinho AA, Agostinho CS, Pelicice FM, Marques EE (2012) Fish ladders: Safe fish passage or hotspot for predation? Neotrop Ichthyol 10: 687-696.

13. Hall SR, Mills EL (2000) Exotic species in large lakes of the world. Aquatic Ecosystem Health and Management 3: 105-135.

14. Born AF (2000) Stock enhancement, Sustainable fish production in Lake Nasser: ecological basis and management policy, World Fish Center, Penang Malaysia.

15. Michael H, Adam B, Andrew N, John K, Keith C (2012)A review of domestication effects on stocked fishes, strategies to improve post stocking survival of fishes and their potential application to threatened fish species recovery programs in the Murray-Darling Basin. Murray-Darling Basin Authority Canberra, Australia.

16. Marshall BE (2000) Alien fish introductions: The African experience and its relevance to Lake Nasser. Sustainable fish production in Lake Nasser ecological basis and management policy. World Fish Center, Penang, Malaysia.

17. De Silva SS (2003) Culture based fisheries: An under utilized opportunity in aquaculture development. Aquaculture 221: 221-243.

18. Beveridge MCM (1984) Cage and pen fish farming. Carrying capacity models and environmental impact. FAO Fisheries Technical Paper 255, Rome.

19. Beveridge MCM, Muir J (1999) Environmental impacts and sustainability of cage culture in Southeast Asian lakes and reservoirs. Fish and fisheries of lakes and reservoirs in Southeast Asia and Africa. Westbury Publishing, Otley, UK.

20. Beveridge MCM, Little DC (2002) History of aquaculture in traditional societies In: B.A. Costa-Pierce, (ed). Ecological Aquaculture. Blackwell Science, Oxford.

21. Balon EK, Coche AG (2012) Lake Kariba, A man-made ecosystem in Central Africa. Monographiae Biologicae.

22. Kolding J, Van Zwieten PAM (2006) Improving productivity in tropical lakes and reservoirs. World Fish Center, Cairo, Egypt.

23. Pavel J, Zdeněk A, Zdenka V, Michal J, Kevin R (2015) Fish community and fisheries management of Brno Reservoir following revitalisation measures. Folia Zool 64: 112-122.

24. Hickley P, Bailey R, Harper DM, Kundu R, Muchiri M, et al. (2002) The status and future of the Lake Naivasha fishery, Kenya. Hydrobiologia 499: 181-190. 